\title{
Sequential Ascus Collection in Neurospora crassa
}

\author{
By W. N. STRICKLAND* AND DEANNA THORPE \\ Department of Biological Sciences, Stanford University, \\ Stanford, California, U.S.A.
}

(Received 21 May 1963)

SUMMARY

A chamber has been devised to collect asci sequentially as they are ejected from individual perithecia of Neurospora crassa. Increasing age of a perithecium brought about a concurrent decrease of crossing-over. The results indicate that the exchange rates are not independent of time.

\section{INTRODUCTION}

In the ascomycete Neurospora crassa, the recovery of asci for tetrad analysis has usually been accomplished by opening the perithecium and dissecting out the mature asci (see Maling, 1960, for discussion). A single perithecium will produce several hundred asci, but only a few of these are mature at any one time. Therefore, the dissection method yields only a small and perhaps non-random sample of the total number developed within a perithecium. Events occurring during the entire life cycle could not be analysed. Under suitable environmental conditions, ascospores of Neurospora crassa are ejected in groups of eight, each group being derived from one ascus (Strickland, 1960). This behaviour suggested a method of recovering asci from a single perithecium in the order in which they were ejected. This paper describes the method of collection of asci and discusses the results obtained.

\section{METHODS}

1187 tetrads were obtained from five perithecia of the cross :

$$
\frac{\text { hist-1(C 84) }+ \text { bis(B 6) }+ \text { pab-2(H 193) }}{+} \frac{\text { ylo (Y 30539y) }}{+} \frac{a}{\mathrm{~A}} \text {. }
$$

Preparation of crosses. Pyrex glass cups, $1 \mathrm{~cm}$. deep, were cut from the bottoms of glass vials, $1 \frac{1}{2} \mathrm{~cm}$. in diameter. These were sterilized and filled with 1-2 ml. supplemented defined crossing medium (Westergaard \& Mitchell, 1947) in $2 \%(\mathrm{w} / \mathrm{v}$ ) agar and placed in a sterile Petri dish. The medium was inoculated with the protoperithecial parent and incubated in the dark at $25^{\circ}$ for 6 days. The resulting cultures were fertilized with a very light dry dusting of conidia and re-incubated in the dark at $25^{\circ}$ for 8 to 9 days. The cups were examined under the microscope and a perithecium selected which was well developed, with its ostiole perpendicular to the agar surfaces. Since a perithecium generally shoots many asci during the first 3 days, close grouping of spores minimizes overlapping of different spore groups. A deviation of the ostiole of more than $5^{\circ}$ from the perpendicular was found to cause poor

* Present address: Department of Microbiology, Dartmouth Medical School, Hanover, New Hampshire, U.S.A. 
grouping of spores accompanying ejection. All other perithecia were removed, leaving the one selected, and the cup was periodically cleared of immature perithecia which developed later. The cup was then placed in a sterile Petri dish and held in position either by a layer of 'Vaseline' or by adding $15 \mathrm{ml} .4 \%(\mathrm{w} / \mathrm{v})$ cool sterile agar. The plate was inverted to allow downward ejection of spores. Agar or parafilm placed on the apposed plate lid was watched carefully for the initial ascus ejection.

Ascus collection chamber. The chamber in which the ascospores were collected is a rectangular stainless-steel box, $130 \mathrm{~cm}$. long $\times 10 \mathrm{~cm}$. wide $\times 9 \frac{1}{2} \mathrm{~cm}$. in depth (see Plate 1). A ledge, extending out $1 \mathrm{~cm}$. horizontally and up $1 \mathrm{~cm}$. vertically, forms a base on which the glass plate cover, $138 \mathrm{~cm} . \times 11 \frac{1}{2} \mathrm{~cm}$., can be placed.

To a tray constructed of stainless steel, $128 \mathrm{~cm} . \times 8 \mathrm{~cm}$. with sides $1 \mathrm{~cm}$. high, was added either $500 \mathrm{ml} .4 \%(\mathrm{w} / \mathrm{v})$ agar or a layer of parafilm cut to fit the tray. The chamber and trays were sterilized with $95 \%$ ethanol.

Outside the chamber, an electric motor turned a pulley wheel with a circumference of $10 \mathrm{~cm}$. at a rate of $1 \mathrm{rev} . / \mathrm{hr}$. Carpet-weight sewing thread was tied around the inverted Petri dish containing the perithecium and passed to the pulley wheel through a hole in one end of the chamber. After the ejection of the first ascus, the perithecium in its Petri plate was placed on the tray in the chamber. The entire apparatus was kept at $25^{\circ}$ under constant fluorescent light. At 12-hr. intervals the Petri dish was rotated so the perithecium travelled over each side and the middle of the agar or parafilm. A single tray was in service for $36 \mathrm{hr}$. After completion of a cycle and replacement by a fresh tray, the first tray was covered with a plastic lid to keep it free from contamination.

When agar was used as the spore-catching surface, the asci were dissected in situ, but when parafilm was used, they were transferred to fresh blocks of $4 \%(w / v)$ agar for dissection. A drop of $\mathbf{5 0 \%}$ sodium hypochlorite was spread around the spores during dissection in order to kill contaminants which germinated before heatshocking. After the time of ejection of each ascus had been recorded, the spores were transferred individually to tubes containing supplemented minimal medium (Vogel, 1956, Microb. Genet. Bull. 13, 42). They were stored at $25^{\circ}$ for 6 days, then heat-shocked at $60^{\circ}$ for $45 \mathrm{~min}$. and germinated at $34^{\circ}$.

\section{RESULTS}

Preliminary work with non-sequential asci obtained by the spore-shooting method occasionally gave clusters of asci with very high recombination frequencies. For short periods during the spore-shooting period of a cross, many groups of eight ascospores were ejected in a localized area, suggesting the activity of a single perithecium. Since these groups were usually dissected together, such a clustering of exchanges suggested a common origin. Therefore, analysis of all the products of a single perithecium was indicated. The collection chamber described here allowed recovery of the entire contents of individual perithecia. Five perithecia were analysed individually and the results shown in Table 1. All germinating ascospores of each ascus were scored for nutritional requirements and visible markers.

By the method of Brownlee (1960), an analysis was made to determine whether exchange or non-exchange tetrads tended to occur in groups. As can be seen from Table 1, runs of either exchanges or non-exchanges are distributed entirely at random. 
Table 1. Distribution of exchanges in sequential ascus analysis from single perithecia of the cross

$$
\frac{\text { hist-1 }+ \text { bis }+}{+ \text { ions }+ \text { pab-2 }} \frac{\text { ylo }}{+} \frac{\text { a }}{\mathrm{A}}
$$

\begin{tabular}{|c|c|c|c|}
\hline \multirow{2}{*}{$\begin{array}{l}\text { Peri- } \\
\text { thecium }\end{array}$} & \multicolumn{2}{|c|}{ Number of runs* } & \multirow{2}{*}{$\begin{array}{l}\text { Total number } \\
\text { of asci }\end{array}$} \\
\hline & Observed & Expected & \\
\hline 1 & 86 & $97 \cdot 9+13 \cdot 13 \dagger$ & 206 \\
\hline 2 & 192 & $189 \cdot 1 \pm 18 \cdot 23$ & 408 \\
\hline 3 & 73 & $78 \cdot 2 \pm 11 \cdot 37$ & 174 \\
\hline 4 & 100 & $97 \cdot 2 \pm 12 \cdot 54$ & 224 \\
\hline $\mathbf{5}$ & 76 & $78 \cdot 6 \pm 11 \cdot 37$ & 175 \\
\hline
\end{tabular}

* A run is a sequence of asci, all of which carry at least one exchange in the chromosome region hist-1 to pab-2, or a sequence of asci in which no exchange can be detected in the same chromosome region.

$+5 \%$ level of significance.

Table 2. Variations in recombination levels in single perithecia of Neurospora

\begin{tabular}{|c|c|c|c|c|c|c|c|c|c|c|}
\hline \multirow[b]{3}{*}{ Perithecium } & \multirow{3}{*}{$\begin{array}{l}\text { Time of } \\
\text { shooting }\end{array}$} & \multirow{3}{*}{$\begin{array}{c}\text { Time } \\
\text { period }\end{array}$} & \multicolumn{5}{|c|}{ Number of recombinant asci in region } & \multirow{2}{*}{\multicolumn{2}{|c|}{ None }} & \multirow[b]{3}{*}{ Total } \\
\hline & & & \multirow{2}{*}{$\begin{array}{l}\text { hist-1 } \\
\text { Obs. }\end{array}$} & \multirow{2}{*}{$\begin{array}{l}\text { inos } \\
\text { Obs. }\end{array}$} & \multirow{2}{*}{$\begin{array}{l}\text { bis } \\
\quad \text { Exp.* }\end{array}$} & \multicolumn{2}{|c|}{$b i s-p a b-2$} & & & \\
\hline & & & & & & Obs. & Exp.* & Obs. & Exp.* & \\
\hline \multirow[t]{5}{*}{$\mathbf{I}$} & $12 \cdot 3$ & $\mathbf{1}$ & $10 \cdot 7$ & 11 & $12 \cdot 4$ & 27 & $\mathbf{2 2 \cdot 5}$ & 49 & $60 \cdot 4$ & 106 \\
\hline & days & $\mathbf{2}$ & $11 \cdot 1$ & 17 & $12 \cdot 9$ & 24 & $23 \cdot 3$ & 62 & $62 \cdot 7$ & 110 \\
\hline & & $\mathbf{3}$ & $7 \cdot 3$ & 11 & $8 \cdot 5$ & 12 & $15 \cdot 5$ & 44 & $41 \cdot 7$ & 73 \\
\hline & & 4 & $7 \cdot 9$ & 4 & $\mathbf{9} \cdot \mathbf{2}$ & 15 & $16 \cdot 7$ & $\mathbf{5 5}$ & $45 \cdot 2$ & 79 \\
\hline & & & $0.05>P>0.02$ & \multicolumn{2}{|c|}{$0.1>P>0.05$} & \multicolumn{2}{|c|}{$0.7>P>0.5$} & \multicolumn{2}{|c|}{$0.3>P>0.2$} & \\
\hline \multirow[t]{3}{*}{ II } & $5 \cdot 0$ & 1 & $7 \cdot 4$ & 11 & $7 \cdot 9$ & 24 & $19 \cdot 6$ & 62 & $70 \cdot 1$ & 105 \\
\hline & days & 2 & $4 \cdot 6$ & 2 & $5 \cdot 1$ & 8 & $12 \cdot 4$ & 53 & $44 \cdot 9$ & 67 \\
\hline & & & $0.8>P>0.7$ & \multicolumn{2}{|c|}{$0.1>P>0.05$} & \multicolumn{2}{|c|}{$0.1>P>0.05$} & \multicolumn{2}{|c|}{$0.2>P>0.1$} & \\
\hline
\end{tabular}

$*$ Expected $=\frac{\text { total asci examined in a given period } \times \text { total asci showing recombination in all periods }}{\text { total asci examined in all periods }}$. 
An analysis was also made to ascertain whether the recombination value remained constant from day to day during the ejection period of a perithecium. Duration of ascospore ejection varied. The ejection period of each perithecium was arbitrarily divided into equal time periods and the data analysed by $\chi^{2}$ method. Perithecium I shot for $12 \cdot 3$ days (Table 2 ). There was a significant decrease of crossing over, all of which occurred in the hist-1-inos interval. Perithecium II shot for 5 days (Table 2) but no significant decreases in recombination level were found. The remaining three perithecia shot for $8.5,6.5$ and 5.2 days, respectively. No significant variation could be detected in the recombination levels from day to day. The proportion of incomplete tetrads remained constant from day to day in all five perithecia analysed.

\section{DISCUSSION}

Two interesting features are evident from the present analysis of single perithecia. (1) Exchanges in the three marked intervals were not clustered in groups, but were distributed at random over the entire shooting period. (2) In one of the five perithecia increasing age brought about a concurrent decrease of crossing over. This decrease occurred in the hist-1-inos interval.

The ascus collection chamber proved to be an effective method for recovering successive asci ejected from a perithecium of Neurospora crassa. It should be a useful tool in the investigation of sequential events within perithecia or cumulative effects of various mutagens and altered environmental conditions.

The authors gratefully acknowledge the suggestions of Dr R.W. Barratt and Dr D. D. Perkins during the course of this work. This investigation was supported by the National Science Foundation, Grant no. 8636 .

\section{REFERENCES}

Brownlee, K. A. (1960). Statistical theory and methodology. Sci. Engng, 5081, 164.

Maling, B. (1960). Replica plating and rapid ascus collection of Neurospora. J. gen. Microbiol. 23, 257.

StrickLand, W. N. (1960). A rapid method for obtaining unordered Neurospora tetrads. J. gen. Microbiol. 22, 583.

Westergand, M. \& Mitchell, H. K. (1947). A synthetic medium favoring sexual reproduction. Amer. J. Bot. 34, 573. 


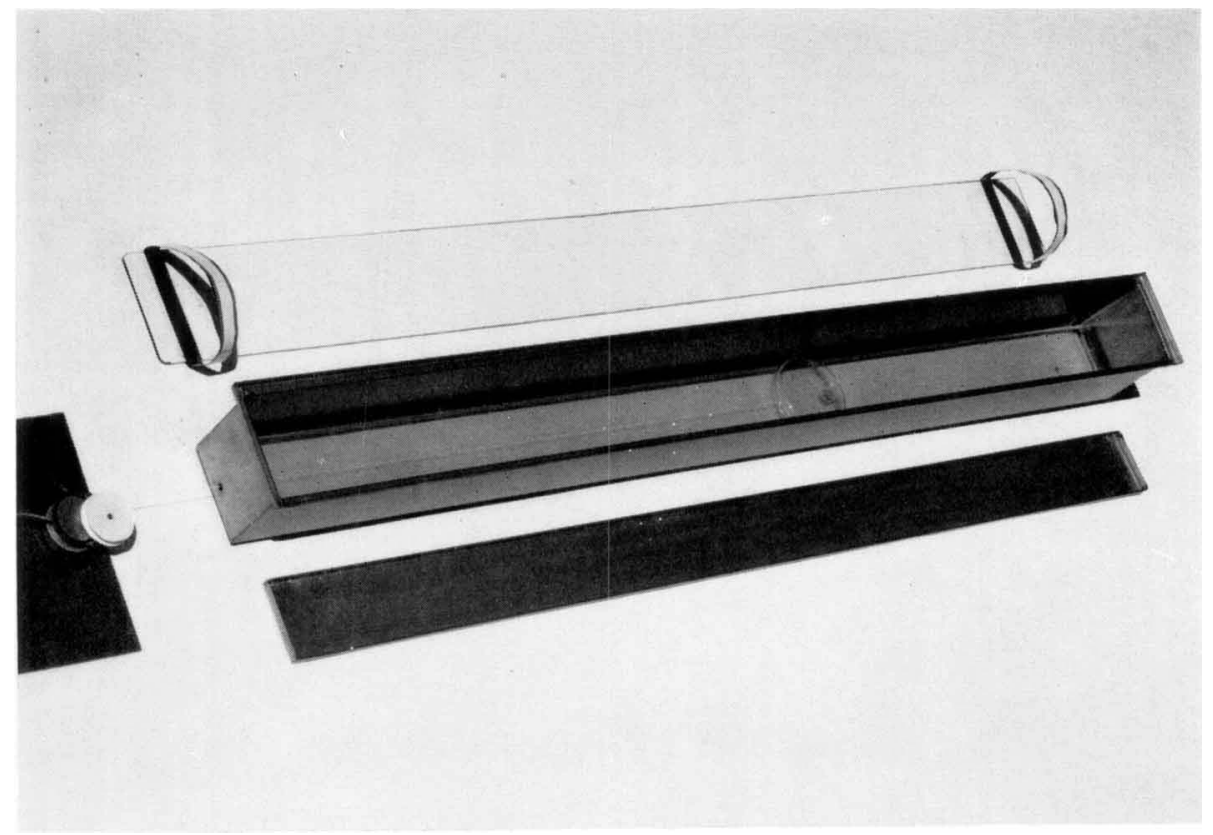

Fig. 1. A chamber for the collection of asci sequentially ejected from individual perithecia of Neurospora crassa. 